$5-2017$

\title{
The Sustainable Future of the Modern Fashion Industry
}

Zhanna Kutsenkova

Dominican University of California

https://doi.org/10.33015/dominican.edu/2017.HONORS.ST.02

Survey: Let us know how this paper benefits you.

\section{Recommended Citation}

Kutsenkova, Zhanna, "The Sustainable Future of the Modern Fashion Industry" (2017).

Honors Theses. 21.

https://doi.org/10.33015/dominican.edu/2017.HONORS.ST.02

This Honors Thesis is brought to you for free and open access by the Student Scholarship at Dominican Scholar. It has been accepted for inclusion in Honors Theses by an authorized administrator of Dominican Scholar. For more information, please contact

michael.pujals@dominican.edu. 


\title{
The Sustainable Future of the Modern Fashion Industry
}

\begin{abstract}
Sustainable fashion is a recent movement within the fashion industry that aims to reduce textile waste and environmental depletion while increasing ethical treatment of workers; the goal is to slow down the global production and consumption process in order to form an industry that will be more sustainable in the long run. Along with the development of more socially and eco-conscious production and marketing practices, there is still room for the sustainable fashion movement to grow beyond its current scope. With the support of growing information networks and brand transparency consumers will be better equipped than ever before to make more ethical purchasing decisions and to potentially change the face of the current fashion industry.
\end{abstract}

\section{Document Type}

Honors Thesis

Degree Name

Bachelor of Arts

Department

Communication and Media Studies

First Reader

John Duvall, PhD

Second Reader

Bradley Van Alstyne, MA

\section{Keywords}

fashion, environment and sustainability

\section{Subject Categories}

Business Law, Public Responsibility, and Ethics | Fiber, Textile, and Weaving Arts 


\title{
The Sustainable Future of the Modern Fashion Industry
}

\author{
Zhanna Kutsenkova
}

Submitted in partial fulfillment of the requirements Bachelors of Arts in Communications and Media Studies

School of Arts, Humanities and Social Sciences

and the Honors Program

Dominican University of California

San Rafael, California

May 2017

First Reader: John Duvall 
Department of Communications and Media Studies

Second Reader: Bradley Van Alstyne

Department of Communications and Media Studies

Honors Director: Dr. Gigi Gokcek

Department of Political Science/International Studies

John Duvall

April 24,_2017

Bradley Van Alstyne

April 24, 2017

Gigi Gokcek

April 24, 2017 


\section{Acknowledgements}

C \& L \& V. я тебя люблю. 


\begin{abstract}
$\underline{\text { Abstract }}$
Sustainable fashion is a recent movement within the fashion industry that aims to reduce textile waste and environmental depletion while increasing ethical treatment of workers; the goal is to slow down the global production and consumption process in order to form an industry that will be more sustainable in the long run. Along with the development of more socially and ecoconscious production and marketing practices, there is still room for the sustainable fashion movement to grow beyond its current scope. With the support of growing information networks and brand transparency consumers will be better equipped than ever before to make more ethical purchasing decisions and to potentially change the face of the current fashion industry.
\end{abstract}


Table of Contents

Introduction........6 6

Research Questions........ 7

What is sustainability?........8

Defining and Differentiating Sustainable Fashion........ 8

Goals of Sustainable Fashion......... 9

Steps in the Sustainable Direction........ 10

Consumers \& Sustainable Fashion.........11

Sustainable Marketing Practices.........14

Sustainable Manufacturing Practices........16

Sustainability and Low Cost Business Models.........18

Intersections Between Business Models \& Corporate Sustainability .........19

Gaps in the Research .........20

Proposed Methodology.........21

Conclusion.........23 


\section{$\underline{\text { Introduction }}$}

The concept of "sustainable fashion" is relatively new -- although the idea of sustainability had been around for decades, it was in the early 90's that designers and innovators first stepped outside of the archetype that encapsulated the fashion industry and explored possibilities beyond what had become the norm for clothing production and consumption. The idea that clothing could be made in a way that would maintain "ecological, social, and cultural diversity" and encourage "innovative business models" grounded what would become a sizeable movement and departure away from the phenomenon of "fast fashion" (Ozdamar, 2015).

With further exploration it becomes evident that there are two leading factors at the forefront of the modern fashion industry -- rabid consumerism and globalization -- the obsession with having the latest trends and the access from mass production fuels the fire of fast fashion and poses a sizeable challenge to the still growing sustainable fashion movement. As both suppliers and consumers become more reliant on speed and low-cost, fast fashion continues to grow with little concern towards the ethical and environmental issues it poses. However, recently the fashion industry has been criticised for the "exploitation of workers, damaging the ecosystem, contributing to the depletion of natural resources, and increasing textile waste" (Ozdamar, 2015). In response to the explicit moral issues of fast fashion, sustainable fashion geared websites, companies, and brands have been able to grow and attract new customers with the transparency of their environmentally and ethically friendly clothing.

As consumers become more wary of the reality of their spending practices and the media as well as new companies are able to provide both information and alternatives, the sustainable fashion movement is able to gain traction, however there is still a long road ahead before 
consumers are able to completely pry away from the readily accessible, mass produced apparel they have become accustomed to.

Despite the many benefits of moving towards the development of the sustainable fashion industry, there has been only moderate success in convincing consumers to make more conscious, sustainable clothing purchases; although with growing awareness of the downfalls of the current apparel industry there may be a more sustainable future in sight. In order to facilitate a change in the global fashion market consumers need to be made more aware of the effects of their clothing purchases and the harsh realities of unethical brands. The realization that nontransparent companies are most likely not producing their goods in an ethical way is an excellent beginning towards encouraging consumers to explore more sustainable options on the market; with the emergence of a new fashion sector there also needs to be a new, multi-faceted marketing approach to develop a stronger, more positive relationship between consumers and brand explicitness, credibility and quality.

\section{$\underline{\text { Research Questions }}$}

R1: What exactly is sustainable fashion and what role does it play in the sustainability movement?

R2: What are the main differences between mainstream, "fast fashion" and sustainable fashion?

R3: What are the key benefits of sustainable fashion?

R4: What are the facets of a sustainable fashion company from a corporate standpoint?

R5: What marketing techniques to companies use to attract new customers?

R6: Is there a connection between consumers who subscribe to environmental activism and those who support and purchase sustainable fashion? 


\section{What is Sustainability?}

Sustainability has become synonymous with environmental activism and has become a movement of its own. The term was first introduced in 1987 when the World Commission on Environmental Development explained that 'sustainable development is development that meets the needs of current generations without compromising the ability of future generations to meet their own needs' (Berfield, 2015). From a wider lense, sustainability is fairly easy to comprehend -- in order to maintain an ecological balance there must be a trade-off between producing, supplying, and purchasing goods and the preservation and maintenance of natural resources. Understanding sustainability does not appear to be a major conflict for researchers and activists, however there has been no successful implementation process suggested as of yet. Sustainability as a movement has gained traction in the business world as a entrepreneurs and CEO's work to create solutions that allow for the formulation of ecologically friendly products that consumers actually desire over their non-sustainable counterparts.

\section{Defining and Differentiating Sustainable Fashion}

Sustainable fashion implies ethics, durability and the reuse of products. A single definition of sustainable fashion is difficult to pinpoint as there is no current industry standard. The concept of sustainable fashion encompasses a variety of terms such as organic, green, fair trade, sustainable, slow, eco etc. (Cervellon et al., 2012), each attempting to highlight or correct a variety of perceived wrongs in the fashion industry including animal cruelty, environmental damage and worker exploitation (Bin, 2014) 
Within the literature, terms are often used interchangeably and frequently for different purposes, for instance, Chan et al (2012) defines 'ethical fashion' as 'fashionable clothes that incorporate fair trade principles with sweatshop free labour conditions while not harming the environment or workers by using biodegradable and organic cotton', whereas Cervellon et al (2012) use 'green fashion' to refer to much the same set of issues.

In order to develop a more comprehensive definition of sustainable fashion there needs to be a more extensive guide to the aspects of consumption such as as laundering, use, reuse and disposal that can have a substantial impact on the sustainability of a garment (Cervellon et al., 2012).

\section{Goals of Sustainable Fashion}

The ultimate goal of the sustainable fashion movement is to massively slow down production and consumption of garments on the global scale (Flower, 2009). The key component of sustainable production is the 'replacement of harmful chemicals with environmentally friendly materials' as well as the reduction of 'waste and resource consumption through apparel recycling' (Flower, 2009). In order to fully comprehend the changes that sustainable fashion suggests it is vital to provide a guideline for ethical production and consumption.

Three crucial elements are necessary to encourage the growth of sustainable fashion: the first is to 'shift consumers' mindsets from quantity to quality by encouraging people to buy highquality items less often'; the second is facilitate production that "does not exploit natural and human resources to expedite manufacturing speed;' and the third is to use consumption to "entail a longer product lifespan from manufacturing to discarding" (Jung et al, 2014).

Academic understanding of slow fashion is currently limited, however with the growth of more sustainable companies and consumer interest there is hope that sustainable fashion will be 
put into practice sooner rather than later. There are many positive effects of adopting a more sustainable fashion system and educated consumers are learning to make more socially conscious purchasing decisions. Without a point of reference it is difficult to qualify the current relationship between consumers and sustainable brands; the research that has been done so far, however, provides a framework that could be used to increase consumer understanding of the negative effects of fast fashion, and the possibility of the development of a sustainable apparel model.

\section{Steps in the Sustainable Direction}

The first anti-fur campaigns appeared in the 1980s, and in the late 1990s, numerous sweatshop scandals surfaced, putting significant social pressure on fashion companies and retailers to implement better monitoring programs over their factories (BSR, 2012). The growing interest in sustainable fashion has been stimulating fashion houses and retailers to take action. Designers such as Stella McCartney and Edun have focused on producing vegan products and establishing fair trade-based relationships (Dach et al, 2014). In 2004, the first Ethical Fashion Show was held in Paris (Hannes et al, 2016). Even established powerhouses, like Louis Vuitton Moët Hennessy Group, got involved by acquiring a 49\% stake in Edun. Further, the trend towards sustainable fashion has also reached large scale fashion brands, such as H\&M with its organic Conscious Collection and MUJI's fair trade products (Lion et al, 2016).

\section{Consumers \& Sustainable Fashion}

Limited research within the literature investigates the motivations driving consumers of sustainable fashion. The vast majority of literature in the field looks down the supply chain (Cervellon et al, 2012) and of the limited number of studies investigating consumer responses to 
sustainable fashion only, Chan et al (2012) purposefully sample sustainable fashion consumers, focusing on how 10 highly vocal online activists define themselves as sustainable fashion consumers. Sustainable fashion consumption research is fairly minimal, however research in the broader context of ethical consumption suggests personal values play a pivotal role in ethical decision-making (Park et al, 2016).

Studies into purchasing behaviour have suggested that consumers have been showing increasing levels of ethical concern in the context of fashion consumption (Pederson et al, 2016). Consumers have become more concerned with the social consequences of their purchases, especially when human rights in factories are violated. Sweatshop labor in particular has been identified as one of the most important ethical concerns when making clothing decisions (Dach et al, 2014).

Of the work there is on sustainable fashion consumption, the majority discuss perceptions of sustainable fashion by the general population, with little work sampling actual consumers of sustainable fashion. the values and motivations underpinning actual sustainable fashion consumption. Chan et al (2012) conducted 39 interviews with a sample of frequent sustainable clothing consumers in an attempt to link purchased products back to purchasing criteria and personal values. In their interviews, clothing that was perceived to be sustainable by consumers needed to last multiple seasons in both durability and style. The interviews determined that participants wanted to have confidence in who they weres, with the main judge being themselves. The need for self-esteem was fulfilled through two chains: comfort and looking good. Value in use in sustainable fashion therefore has both physical and psychological benefits that help the consumers feel better about themselves. However, even when talking about the physical benefit of looking good, consumers expressed that although they do care about their 
appearance, it is not based on the perception of others, but of themselves. The chain of unique styles and sense of individuality was also driven by a second value, namely, that of selfexpression. The participants referred to self-expression as being able to voice their personality, values and opinions through their clothing. Buying clothes made from natural materials was considered as one of the smallest things that they can do to help the environment. This connection underlined the importance of natural materials of a product as an attribute of immense importance to consumers. Participants also related to clothes that had been made using environmentally friendly production techniques. Participants revealed that they 'enjoyed the feeling of doing the right thing' and expressed the need for confirmation of having made the correct decisions.

McNeill et al (2015) conducted a survey that aims to explore fashion consumers' attitudes toward the consumption of sustainable fashion and identify the impact of the 'fast fashion' on these attitudes. All participants in the study cited fashion and clothing as having a certain level of importance to them. However, where some participants noted that fashion was important ethically and stated that they believed all consumption should be meaningful, others felt that fashion's importance was centered on 'fitting in' and the social norms of fashion consumption (McNeill et al, 2015). While the survey discussed and addressed many elements of consumers's attitudes towards sustainable fashion and their average consumption pattern in the apparel realm, it allows for a certain level of subjectivity when it comes to the most successful method for attracting customers to a new sustainable fashion company. Several elements of their results are able to be used to draw further conclusions about consumer behavior and patterns, and what fuels any person to make an investment in fashion -- as customers increase their awareness of the 
negative implications of their addictions to fast fashion, their consuming habits have a tendency to change (Bin, 2014).

Jägel et al. (2012) study is a rare example of motivation driven research into sustainable fashion (or even ethical consumption generally). They explore hypothetical and future purchases covering a range of 'sustainability' issues on consumers who self-report having performed at least one of the following: recycling clothing, boycotting a company and buying eco or fair trade clothing. They report a relatively high incidence of ethical values such as social justice, equality and supporting the environment as underpinning their hypothetical consumption behaviours.

Consumers are driven partially by ethical obligations (Press et al, 2014). For example, consumers want to reduce waste and support the environment. Similarly, they are motivated by the knowledge that they are reducing risks for other members in society through buying products that have not exploited workers and supporting communities. Yet, the consumers may simultaneously seek individual benefits such as comfort, individuality, looking good and various aspects of design in sustainable fashion, all of which are related to hedonic consumption (Press et al, 2014) of the consumers would continue to consume for purely altruistic reasons. As such, the market for sustainable fashion will likely stick to the high quality and premium clothing end of the spectrum for some years to come. Entering the market with lower quality and cheaper clothing may have the impact of undermining the strong associations frequent consumers have with the use of high-quality, durable, natural materials. Ultimately, this does create a glass floor, below which sustainable suppliers may be unable to compete with altruistic marketing communications. It could also undermine the use of non-natural materials - even if life cycle studies suggest these may have lower environmental footprints long term. 
There is also an issue regarding how brands communicate sustainability. There has been a much larger rise in the use of terms such as eco-fashion or fair trade fashion in brand communication. In terms of attracting new customers, key selling features of sustainable fashion revolve around timeless cuts, unique cuts, durability, natural materials and perceived health benefits. These are all selling points that could entice less altruistic consumers to buy brands as well. They speak to egotistical needs and promote value to consumers that in turn would be reflected in the premium prices. By reducing the consumers need to source information or become educated about fashion through carefully selected public relations and marketing campaigns, sustainable fashion brands could focus on the egotistical benefits of their products to attract an increasing number of consumers.

\section{Sustainable Marketing Practices}

Within the fashion industry, there has been a great deal of exploration of the most potent marketing practices to draw potential consumers or even entire demographics towards brands or products. There has been little research, however pertaining to sustainable fashion marketing. Identity marketing is one such facet of global business strategy that aims to create a "connection between consumer identity and the likelihood to subscribe to certain brands" (Bhattacharjee et al, 2014). Recent studies show that often explicit identity-marketing messages are not as effective in connecting a particular brand to a consumer's identity (Bhattacharjee et al, 2014). Through a comparison of efficacy within message content, the messages that "specifically define identity expression are more likely to reduce purchase likelihood than those that merely suggest a relevance of a product towards the consumer's particular demographic and lifestyle" (Bhattacharjee et al, 2014). This particular research, despite its potentially large sample size, 
continuous implementation, and plausible analysis has an evident drawback -- it does not delve deeply into specific marketing approaches used by brands to target their key demographics, whether it be by age, race, gender, level of education, etc., it leaves an ambiguous and generalized definition of identity marketing and its potential potency. Research of consumer behavior is crucial to understanding consumer response to feeling defined by brands rather than feeling free to make the choice based on their specific needs (Chan et al, 2012).

Brand transparency has been classified as a major component of successful sustainable fashion marketing. It is crucial that consumers understand where their clothes are being made and what materials are being used to create them. Several studies have been conducted to examine how and why consumers respond to brand name and message explicitness. Yan et al (2012) observed the efficacy of these two variables by administering a questionnaire to 342 college students with questions geared towards examining whether or not they would respond to products labeled as "environmentally friendly." They hoped to attract college students towards brands that were honest about their production, materials, and level of sustainability. The results of their survey revealed that terms such as eco, green, natural, organic, and sustainable were not conducive to increased product sales. They did find that the most effective way to garner more attention towards environmentally friendly apparel goods was to formulate a multifaceted marketing approach that highlights selling points such as brand name, comfort, quality, low price, etc, instead of employing a single eco-product strategy. Their research clearly indicates that attitude toward brand, eco-fashion involvement, and environmental commitment were strong predictors of intention to purchase an environmentally friendly apparel brand.

With this information, it can be inferred that for apparel marketers to build more positive attitudes towards brands, they must provide explicit information about environmentally friendly 
products in their marketing claims. This may be one way for marketers to attract college students who are interested in purchasing environmentally friendly products, but who are not fully committed to a green lifestyle. Further, marketers may be able to reach those who are less interested in purchasing environmentally friendly products by raising awareness and knowledge of the benefits associated with their products and brands, which may help to establish a sustainable market for eco-fashion (Dong et al, 2013).

\section{Sustainable Manufacturing Practices}

The issue of sustainability in the corporate industry is constantly growing as both corporate managers and academics stress the need to integrate sustainability into corporate strategy to both ‘create competitive advantages and mitigate sustainability problems' (Egels-Zanden, 2015).

Although several studies suggesting how sustainability could potentially be integrated into strategy have been conducted, there have been few that specifically follow corporate attempts to incorporate sustainability into their company mission. Egels-Zanden's (2015) study of the downfalls and triumphs of creating a fully sustainable company is one of the few to provide a framework for the inner workings of the "most transparent company in the world" -- Swedish based Nudie Jeans Co.. The company runs on the ultimate goal of integrating social sustainability into strategy in global value chains by creating a corporate ideal that enforces slow production as well as "full transparency" (Egels-Zanden, 2015). Nudie Jeans Co addresses worker rights by only sourcing from democratic countries with acceptable working conditions, disclosing all manufacturing practices both within and out of the company to the consumers, and fostering a corporate culture based on fully transparent marketing practices (Egels-Zanden, 2015). 
The possibility of more companies adopting the policy of complete transparency, is both positive and vague -- consumers could potentially respond to well to brand honesty or with confusion. Without an apt understanding of harmful materials and working conditions, consumers may not be able to differentiate between the companies who disclose little to no information versus those who choose to disclose all of it. An ethnographic approach in future studies, along with first hand observations and interviews would be beneficial in increasing the understanding of feasible marketing, production, and consumption strategies -- there is hope, however, that as more sustainable companies emerge, non-sustainable companies may follow their lead and create a shift in the current corporate culture.

\section{$\underline{\text { Sustainability and Low Cost Business Models }}$}

Although corporate sustainability has not been directly correlated with a better brand image or improved control over valuable supplier relationships, it has been shown to minimize the "downside risk of the business model" (Lueg et al, 2015). This process is ensured by "creating implicit contracts that reach beyond traditional "shareholder value, transferring risk to suppliers, and improving leadership by motivating management and employees, and by directing more attention to critical issues" (Lueg et al, 2015). Corporate sustainability adds to increased shareholder value as a more effective control over suppliers, and provide a framework that could 
potentially introduce ' mandatory disclosure of suppliers or to establish an industry-wide comply-or-explain code of conduct.'

The rise of global markets and the ability to generate clothing faster to meet consumer demand has created a low cost business model that is far from ethically charged, however, there is no current information that suggests that the model cannot be improved or even regenerated to become more sustainable. Lueg et al (2015) conducted a case study on the role of corporate sustainability in a large Scandinavian clothing and apparel company (SCAC). The essential role of a Scandinavian setting in this study is a condensed example of sustainability in what is generally considered to be a more politically and governmentally flexible environment. The implication is that sustainability actually adds value to a low cost business model. Although the goal of the SCAC is not necessarily altruistic, it does offer the potential to "triple the bottom line of economic, social, and environmental company performance" as well as to meet the stakeholders' expectations for production (Lueg et al, 2015). Although it has been proven that there are little to no negative effects of corporate sustainability, this study highlights the distinct gap in research. However, it is evident that a further understanding of the value of sustainability and the effects of modern fashion practice (including production, branding, etc.) could have a great impact on the future of the globalized fashion industry.

\section{Intersections Between Business Models \& Corporate Sustainability}

Although social and environmental challenges in the fashion industry are not acknowledged, understanding of a connection between business models and corporate sustainability is still limited. In a survey of responses from 492 managers within the Swedish fashion industry Pedersen et al (2016) concluded that companies with innovative business 
models are more likely to "address corporate sustainability and that business model innovation and corporate sustainability alike are typically found in organisations rooted in values of flexibility and discretion." The study also found a connection between organizational values and financial performance. Certain business models, it appears, have a greater capacity to implement sustainable corporate practice. Conventional business models have been challenged within the fashion industry to what can be classified as a great extent, whether it be towards using new resources or new revenue channels, companies have introduced new sustainability initiatives gradually. A number of fashion brands, including Patagonia, Levi’s, and H\&M among others, have individually or in partnership with other organizations, introduced various take-back, resell, reuse, and recycle programs (Pedersen et al, 2016). These new business models are only the beginning to the tackling of fundamental challenges, but they mark a poignant beginning in both progress and experimentation. In the context of the fashion industry, Pedersen, Gwozdz, \& Hvass define corporate sustainability as 'meeting the needs of the firm's direct and indirect stakeholders (such as shareholders, employees, clients, pressure groups, communities etc.), without compromising its ability to meet the needs of future stakeholders as well.' Towards this goal, firms have to maintain and grow their economic, social and environmental capital base while actively contributing to sustainability in the political domain."

Emerging research on sustainable business models notes several important discretions: 'while mainstream business model thinking tends to give primacy to customers, corporate sustainability literature expands the organisational boundaries to include a wider set of stakeholders (e.g. non governmental organisations, local communities, and the environment).' The development of more innovative models is not only relevant to the success of a company, but creates the potential to generate positive or "eliminate negative societal impacts" from the 
fashion industry as a whole (Pedersen et al, 2016). In order to create a business model that is not only innovative but flexible for future growth, the re-prioritization of stakeholders is essential.

\section{Gaps in the Research}

Sustainable fashion is a rapidly growing concept that is not yet fully understood academically. Through a thorough examination of several forms of research centered around the emerging phenomenon of sustainable fashion, there are several gaps that could provide the most successful context for mobilizing the movement through the global market. First, there must be a clear and accessible way to inform all demographics about the definition of sustainable fashion, the harsh realities of standardized clothing production and manufacturing, and the necessity to move away from subscribing to fast fashion in order to create a greater social, ecological, and economic sustainability (Cervellon et al, 2012). Secondly, a marketing approach that is sustainable for both the eco-conscious and those willing to learn must be created in a way that makes sustainable fashion easily understandable, accessible, and equally as appealing as fast fashion (Park et al, 2016).

\section{Proposed Methodology}

Although sustainable fashion has garnered attention from academics, brands, and consumers, research is still tethered by limitations enforced by the rapid globalization and normalization of "fast fashion." In seeking to understand and enhance current research, I began by conducting a thorough literature review, and I found that there are gaps in the literature that need to be filled. To create an overlapping, umbrella definition of what constitutes sustainable fashion there needs to be a consistent message that establishes sustainable fashion as a socially 
conscious movement as well as a deviation away from the exploitation of natural and human resources. Furthermore, to establish a connection between consumers and informed purchasing decisions, it is also crucial to present the concept of sustainable consumption as a way of both supporting environmental sustainability as a whole as well as the subset of sustainable fashion (Jung et al, 2014).

Another element of my research revealed inadequacies in the study of corporate sustainable practices. There is currently limited research about the success of marketing strategies for sustainable fashion. To formulate the multifaceted approach that several studies suggest, including highlighting major selling points such as brand name, comfort, quality, low price, etc., there needs to be observation of both completely ethical and sustainable fashion companies as well as those beginning to adopt a more transparent approach to their production and distribution practices. Egels-Zanden (2015) provides a particularly excellent model of this method through his observation of a one hundred percent transparent sustainable fashion company. His simple approach to examining a functioning corporate strategy provides tangible evidence towards the notion that corporate culture can shift. By specifically referencing the ethical and sustainable ways the company produces and sells their product and cross-comparing it with the growth of the company, Egels-Zanden succeeds in presenting a concrete example of an effective marketing, production, and consumption strategy. As a starting point for my own research I can use the values of measurement Egels-Zanden employed to conduct my own research focusing on sustainability and strategy in a changing corporate culture. To conduct my own analysis of the benefits and losses of complete brand transparency I would need to observe a specific marketing approach (potentially a multi-faceted marketing approach) by a single company. 
Another element of my future research into the sustainable fashion industry will be interviews. Along with interviewing someone either employed at or running an ethical fashion company, I look forward to conducting interviews with sustainable fashion designers with either their own lines (which they may sell online or in store). To narrow what is a largely broad topic often too intermingled with the hegemony of the environmentalist movement, I will need to begin with a smaller, more qualitative approach so that I may understand how designers were first introduced to sustainable fashion, what materials they use to create their clothing, and what they hope will be the future of the sustainable fashion industry. With further elaboration from those actively working and keeping up with the field I may be able to gain a level of expertise that can only be acquired through personal experience.

\section{Conclusion}

Sustainable fashion is a burgeoning sector of the apparel industry with the potential to grow exponentially as consumers become more informed of the unethical treatment of workers and ecologically depleting production practices of the fast fashion industry. By slowing down consumption and production patterns, the fashion industry can be made more sustainable for the future. In order to achieve the results the movement desires, consumers must be faced with the realization that the non-transparent, fast fashion giants they actively subscribe to are not making a positive social or environmental impact. Along with more educated consumers, companies must develop multi-faceted marketing approaches that go beyond keywords like "green" or "ecofriendly" and entice customers towards their product quality, comfort, and brand name. Sustainable fashion could potentially change the way people consume and the way companies 
produce, with the correct balance of the two, an incredibly positive socially and environmentally beneficial effects would ensue. 


\section{References}

BHATTACHARJEE, A., BERGER, J., \& MENON, G. (2014). When Identity Marketing Backfires: Consumer Agency in Identity Expression.Journal Of Consumer Research, 41(2), 294-309. doi:10.1086/676125

Bin, S. (2014). Sustainable Fashion Supply Chain: Lessons from H\&M. Sustainability (2071-1050), 6(9), 6236. doi:10.3390/su6096236

Berfield, S. (2015). Making Ethical Chic. Bloomberg Businessweek, (4454), 56.

Cervellon, M., \& Wernerfelt, A. (2012). Knowledge sharing among green fashion communities online Lessons for the sustainable supply chain. Journal Of Fashion Marketing \& Management, 16(2), 176. doi:10.1108/13612021211222860

Chan, T., \& Wong, C. W. (2012). The consumption side of sustainable fashion supply chain Understanding fashion consumer eco-fashion consumption decision. Journal Of Fashion Marketing \& Management, 16(2), 193. doi:10.1108/13612021211222824

Dach, L., \& Allmendinger, K. (2014). Sustainability in Corporate Communications and its Influence on Consumer Awareness and Perceptions: A study of H\&M and Primark. Procedia - Social And Behavioral Sciences, 130(4th International Conference on Marketing and Retailing 2013, INCOMaR 2013), 409-418. 
DONG, S., RICHARDS, J., \& FENG, L. (2013). CONSUMERS' AWARENESS OF SUSTAINABLE FASHION. Marketing Management Journal, 23(2), 134-147.

Egels-Zandén, N. (2016). Not made in China: Integration of social sustainability into strategy at Nudie Jeans Co. Scandinavian Journal Of Management, 3245-51. doi:10.1016/j.scaman.2015.12.003

Flower, G. (2009). Sustainable appeal: the slow fashion movement. Alive: Canada's Natural Health \& Wellness Magazine, (324), 98-101 4p.

H \& M Hennes \& Mauritz AB SWOT Analysis. (2016). H \& M Hennes \& Mauritz AB SWOT Analysis, 1-8.

Jung, S., \& Jin, B. (2014). A theoretical investigation of slow fashion: sustainable future of the apparel industry. International Journal Of Consumer Studies, 38(5), 510. doi:10.1111/ijcs.12127

Lion, A., Macchion, L., Danese, P., \& Vinelli, A. (2016). Sustainability approaches within the fashion industry: the supplier perspective. Supply Chain Forum: International Journal, 17(2), 95-108. doi:10.1080/16258312.2016.1176752

Lueg, R., Pedersen, M. M., \& Clemmensen, S. N. (2015). The Role of Corporate Sustainability in a Low-Cost Business Model - A Case Study in the Scandinavian Fashion Industry. 
Business Strategy \& The Environment (John Wiley \& Sons, Inc), 24(5), 344-359. doi:10.1002/bse. 1825

McNeill, L., \& Moore, R. (2015). Sustainable fashion consumption and the fast fashion conundrum: fashionable consumers and attitudes to sustainability in clothing choice. International Journal Of Consumer Studies, 39(3), 212. doi:10.1111/ijcs.12169

Ozdamar Ertekin, Z., \& Atik, D. (2015). Sustainable Markets: Motivating Factors, Barriers, and Remedies for Mobilization of Slow Fashion. Journal Of Macromarketing, 35(1), 53. doi:10.1177/0276146714535932

Park, H., \& Kim, Y. (2016). Proactive versus reactive apparel brands in sustainability: Influences on brand loyalty. Journal Of Retailing And Consumer Services, 29114-122. doi:10.1016/j.jretconser.2015.11.013

Pedersen, E. G., Gwozdz, W., \& Hvass, K. K. (2016). Exploring the relationship between business model innovation, corporate sustainability, and organisational values within the fashion industry. Journal Of Business Ethics, doi:10.1007/s10551-016-3044-7

Press, M., \& Arnould, E. J. (2014). Narrative transparency. Journal Of Marketing Management, 30(13-14), 1353. doi:10.1080/0267257X.2014.925958

Reilly, A. H., \& Hynan, K. A. (2014). Corporate communication, sustainability, and social 
media: It's not easy (really) being green. Business Horizons, 57(SPECIAL ISSUE: INBAM), 747-758. doi:10.1016/j.bushor.2014.07.008

Steiner, P. H., \& Maas, P. (2014). Bringing Together Social Media and Sustainability: Sustainable

Social Media Users Tell More. AMA Winter Educators' Conference Proceedings, 25M-7-M-8.

Yan, R., Hyllegard, K. H., \& Blaesi, L. F. (2012). Marketing eco-fashion: The influence of brand name and message explicitness. Journal Of Marketing Communications, 18(2), 151-168. doi:10.1080/13527266.2010.490420 
This thesis, written under the direction of the candidate's thesis advisor and approved by the Chair of the undergraduate program, has been presented to and accepted by the Faculty of the Department of Communications and Media Studies in partial fulfillment of the requirements for the degree of Bachelor of Arts. The content and research methodologies presented in this work represent the work of the candidate alone.

Zhanna Kutsenkova

April 24, 2017

[Your Name], Candidate

Date

Bradley Van Alstyne

April 24, 2017

Bradley Van Alstyne, Chair, Second Reader

Date

Dr. John Duvall

April 24, 2017

Dr. John Duvall, Thesis Advisor

Date 